\title{
Optical and EPR study of precipitated phases in $\mathrm{NaBr}: \mathrm{Mn}^{2+}$
}

\author{
C Marco de Lucas, F Rodríguez and M Moreno \\ DCITTYM, (Sección Ciencias de Materiales), Facultad de Ciencias, Universidad de \\ Cantabria, 39005 Santander, Spain
}

Received 8 June 1989

\begin{abstract}
As-grown $\mathrm{NaBr}: \mathrm{Mn}^{2+}$ crystals have been investigated using photostimulated luminescence, EPR and optical absorption techniques in the $6 \mathrm{~K}-300 \mathrm{~K}$ temperature range. Through them the formation of a precipitated phase involving $\mathrm{Mn}^{2+}$, whose magnetic phase transition temperature is well below $6 \mathrm{~K}$, is established. This conclusion then supports the presence of the Suzuki phase previously inferred from Raman data. The value $\Omega^{*}\left(\mathrm{~A}_{1 \mathrm{~g}}\right)=$ $130 \pm 7 \mathrm{~cm}^{-1}$ derived at $14 \mathrm{~K}$ from the vibrational progression in the ${ }^{4} T_{1}(G)$ band concurs with the corresponding Raman value. It is shown that, only through the ${ }^{4} A_{i}(G),{ }^{4} \mathrm{E}(\mathrm{G})$ peak, lying at $419.6 \mathrm{~nm}$ at $14 \mathrm{~K}$ for the present case, the presence of $\mathrm{MnBr}_{5}^{4-}$ cannot be definitely established. This situation is however improved by looking at the Stokes shifts, the $10 \mathrm{Dq}$ values and also the optical bandwidths.

The analysis of $10 \mathrm{Dq}$ and $\Omega\left(\mathrm{A}_{1 \mathrm{~g}}\right)$ suggests that the $\mathrm{Mn}^{2+}-\mathrm{Br}^{-}$distance $R$ is higher than that for $\mathrm{MnBr}_{2}$ or $\mathrm{Cd}_{0.85} \mathrm{Mn}_{0.15} \mathrm{Br}_{2}$. However an increase $\Delta R=4.8 \mathrm{pm}$ with respect to $\mathrm{MnBr}_{2}$ does not fully account for the 'anomalous' ${ }^{4} A_{1}(G),{ }^{4} E(G)$ peak position in the present case where a value $J=0.014 \mathrm{~cm}^{-1}$ has been derived for the exchange constant from the EPR bandwidth $\Delta H_{\mathrm{pp}}=117 \mathrm{G}$.

Attention has been paid to the influence of temperature changes on the optical peak positions as well as to the effects of a quenching at $600^{\circ} \mathrm{C}$. Although $\Delta H_{\mathrm{pp}}$ becomes 2.5 times higher, no evidence is obtained on the formation of isolated $\mathrm{Mn}^{2-}$ ions after quenching.
\end{abstract}

\section{Introduction}

The formation of precipitated phases (PF) in doped insulator materials is a rather common phenomenon which occurs even for impurity concentrations well below $1000 \mathrm{ppm}$. A summary of this field of research is given in the review of Agulló-López et al [1].

The interest in studying the precipitated phases formed inside a known host lattice is mainly due to the two following factors:

(i) microcrystals of new materials with different composition, crystal structure and physico-chemical properties from those of known compounds can be formed;

(ii) the macroscopic properties of microcrystalline precipitated phases can be good candidates for revealing size and surface effects.

The Suzuki phase (SP) formed in as-grown $\mathrm{NaCl}: \mathrm{Mn}^{2+}$ crystals [2] is a good example for illustrating both possibilities. In fact up to date no single crystals of the composition $\mathrm{Na}_{6} \mathrm{Cl}_{8} \mathrm{Mn}$ corresponding to the SP have been reported although microcrystals of such a 
phase can be easily formed in $\mathrm{NaCl}$ doped with $\mathrm{MnCl}_{2}$. Despite the great distance of $797 \mathrm{pm}$ between closest $\mathrm{Mn}^{2+}$ ions [2], it has been demonstrated that the microcrystals of $\mathrm{Na}_{6} \mathrm{Cl}_{8} \mathrm{Mn}$ undergo a para-antiferromagnetic phase transition at $0.2 \mathrm{~K}[3,4]$. Moreover, the magnetisation data below that temperature [4] reveal the presence of loose spins associated with $\mathrm{Mn}^{2+}$ in the surface seeing an internal field smaller than that for $\mathrm{Mn}^{2+}$ ions in the bulk. The nature of the precipitated phase appears to depend significantly on the host lattice. This way the precipitated phase formed in $\mathrm{RbCl}_{2}: \mathrm{Mn}^{2+}$ corresponds neither to the sP nor to $\mathrm{MnCl}_{2}, \mathrm{RbMnCl}_{3}, \mathrm{Rb}_{2} \mathrm{MnCl}_{4}$ or $\mathrm{Rb}_{3} \mathrm{Mn}_{2} \mathrm{Cl}_{7}$, and exhibits a magnetic phase transition at $T_{\mathrm{N}}=72 \pm 5 \mathrm{~K}[5]$.

At variance with what happens for a pure compound, knowledge of the composition and crystal structure of precipitated phases is in principle more difficult, especially for impurity concentrations lower than $\sim 10^{3} \mathrm{ppm}$. In fact, in such a case x-ray diffraction methods are not sensitive enough for detecting the precipitates. Therefore in this rather usual situation the use of several complementary techniques appears to be necessary for gaining a good insight into the nature of the precipitates as well as for exploring their properties.

Owing to both circumstances, special attention has been paid to precipitated phases involving transition metal cations like $\mathrm{Mn}^{2+}, \mathrm{Ni}^{2+}$ or $\mathrm{Co}^{2+}$ which are magnetically and optically active $[1,4-8]$.

This makes it possible to use the EPR and optical techniques (optical absorption, photoluminescence) in the investigation of the precipitated phases in conjunction with other general techniques which can be applied to any kind of precipitated phase involving spectroscopically inactive cations like $\mathrm{Sr}^{2+}, \mathrm{Ca}^{2+}$ etc. Examples of these general techniques are Raman spectroscopy [9], electron microscopy [10] and small-angle neutron scattering [11].

For the case of $\mathrm{PF}$ involving cations like $\mathrm{Mn}^{2+}, \mathrm{Ni}^{2+}$ etc and formed inside host lattices like $\mathrm{NaCl}, \mathrm{MgO}$ etc the EPR and optical techniques have the advantage of their sensitivity and selectivity, which means that the detected signals essentially arise from the PF. Moreover, both techniques have revealed to be useful for detecting the formation of PF as well as for identifying easily a given PF through spectroscopic means. As regards the optical techniques, for instance, the observation of double excitation bands plays an important role for both purposes $[5,6,12,13]$. Up to now the PF formed in $\mathrm{NaCl}$ doped with divalent cations have received particular attention, while less work has been devoted to other alkali halide lattices [1].

Recently it has been pointed out that the Raman spectra of as-grown $\mathrm{NaBr}: \mathrm{Mn}^{2+}$ are consistent with the formation of the sP precipitates [14]. The frequency of the $A_{1 g}$ breathing mode around $\mathrm{Mn}^{2+}$ is $\Omega=126 \mathrm{~cm}^{-1}$ at room temperature. The main goal of the present work is just to investigate samples of the same as-grown $\mathrm{NaBr}: \mathrm{Mn}^{2+}$ crystal using optical and EPR techiques in the 6-300 $\mathrm{K}$ temperature range. Besides supporting the existence of the SP in our as-grown $\mathrm{NaBr}: \mathrm{Mn}^{2+}$, we are also interested in analysing the differences between its crystal-field spectrum and that corresponding to other systems, like $\mathrm{MnBr}_{2}$ [15-20], $\mathrm{Cd}_{0.85} \mathrm{Mn}_{0.15} \mathrm{Br}_{2}$ [21] and $\mathrm{CsMnBr}_{3}$ [22], involving $\mathrm{MnBr}_{6}^{4-}$ units as well. Apart from the scarce data on systems with $\mathrm{MnBr}_{6}^{4--}$ units, another reason for this study is to know to what extent the crystal field peaks can be understood only on the basis of $\mathrm{MnBr}_{6}^{4-}$ units but whose $\mathrm{Mn}-\mathrm{Br}$ distance $R$ depends on the lattice. In this line also we explore through this work whether the position of the ${ }^{4} A_{1}(G),{ }^{4} E(G)$ peak corresponding to an $\mathrm{MnX}_{6}$ complex can clearly determine the nature of the ligand $\mathrm{X}$ or not [23].

Besides this research on as-grown $\mathrm{NaBr}: \mathrm{Mn}^{2+}$, the effects of quenching at $600{ }^{\circ} \mathrm{C}$ upon excitation, emission and EPR spectra will also be considered. 
Although to our knowledge no research on as-grown $\mathrm{NaBr}: \mathrm{Mn}^{2+}$ by means of EPR and optical techniques has been carried out to date, some results on $\mathrm{NaBr}$ doped with $\mathrm{Mn}^{2+}$ and $\mathrm{Eu}^{2+}$ have recently been reported [24]. Such data will be compared to the present ones where no sensitiser has been introduced for detecting $\mathrm{Mn}^{2+}$ luminescence.

\section{Experimental procedure}

The $\mathrm{NaBr}: \mathrm{Mn}^{2+}$ crystal studied in this work was grown in the crystal growth laboratory of the Universidad Autónoma (Madrid). Samples of the same crystal were used for the Raman measurements previously carried out by De Andrés et al [14]. The actual $\mathrm{Mn}^{2+}$ content was measured by atomic absorption spectrophotometry, being equal to about $500 \mathrm{ppm}$. Due to the hygroscopic nature of $\mathrm{NaBr}$, the crystal was kept under an argon atmosphere. A dry box was used for placing the samples in the cryostat for optical experiments. In the EPR experiments $\mathrm{NaBr}: \mathrm{Mn}^{2+}$ samples were protected by paraffin oil. Quenching was achieved by heating the sample at $600^{\circ} \mathrm{C}$ for two hours and dropping it suddenly onto a copper block. Optical absorption data in the $190-3300 \mathrm{~nm}$ range were recorded using a Perkin-Elmer Lambda 9 spectrophotometer.

The emission and excitation spectra as well as lifetime measurements were performed through a Jobin-Yvon JY3D spectrofluorimeter improved in our laboratory [25]. A continuous xenon lamp was used as excitation source. Data acquisition for lifetime measurements was carried out by means of an HP $89064 \mathrm{~A}$ analog input card attached to an HP series 300 microcomputer. More details are given in [26].

Temperature variations for the optical experiments were achieved by means of an Air Products model CSA-202E closed-circuit cryostat. EPR spectra in the $6 \mathrm{~K}-300 \mathrm{~K}$ temperature range were taken at the Laboratoire de Spectroscopie du Solide (Le Mans, France) and at the Laboratoire de Chimie du Solide (Bordeaux, France). Different samples of the as-grown $\mathrm{NaBr}: \mathrm{Mn}^{2+}$ crystal were studied by optical and EPR techniques. The same result was obtained in all cases.

The procedure followed for deriving the effective Racah parameters $B$ and $C$ as well as the cubic field splitting $10 \mathrm{Dq}$ from the experimental crystal field spectra is the same for all the systems discussed through this paper. In such a fitting, Tree's $(\alpha)$ and seniority $(\beta)$ parameters are considered and taken equal to $\alpha=65 \mathrm{~cm}^{-1}, \beta=-131 \mathrm{~cm}^{-1}[27,28]$.

\section{Spectroscopic characterisation of as-grown $\mathrm{NaBr}: \mathrm{Mn}^{2+}$ samples}

The optical absorption spectrum of as-grown $\mathrm{NaBr}: \mathrm{Mn}^{2+}$ samples does not show any absorption band in the $700-3000 \mathrm{~nm}$ region, even using crystals $2 \mathrm{~cm}$ thick. This means that the $\mathrm{OH}^{-}$concentration is not higher than about $1 \mathrm{ppm}$. In the $200-700 \mathrm{~nm}$ no traces of $\mathrm{Mn}^{2+}$ absorption have been detected. Nevertheless below about $600 \mathrm{~nm}$ the optical density increases progressively following a $\lambda^{-4}$ law. This supports the presence of precipitates inside the $\mathrm{NaBr}$ host matrix giving rise to Rayleigh scattering.

The EPR spectra for as-grown $\mathrm{NaBr}: \mathrm{Mn}^{2+}$ at several temperatures are portrayed in figure 1. It consists only of an isotropic signal with a truncated Lorentzian shape and centred at $g=2.017$.

The shape of the band is similar to that found for compounds of $\mathrm{Mn}^{2+}$ [29] (such as $\mathrm{MnF}_{2}$ ) and in as-grown $\mathrm{NaCl}: \mathrm{Mn}^{2+}$ [30] and $\mathrm{RbCl}: \mathrm{Mn}^{2+}$ [5] crystals where $\mathrm{PF}$ are 


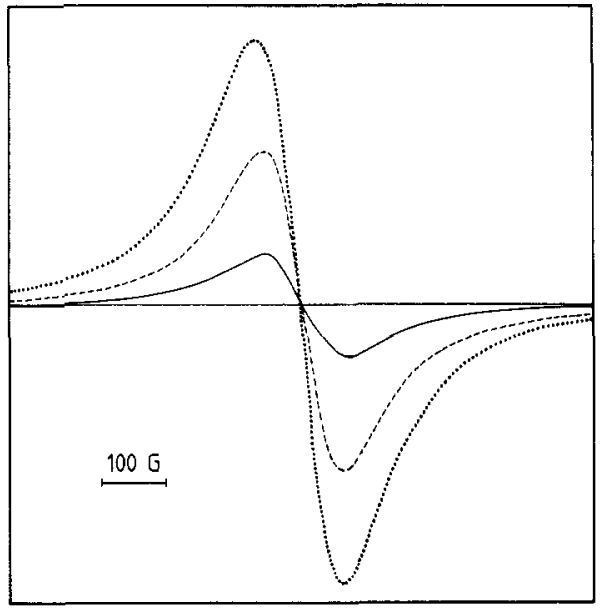

Figure 1. EPR spectrum, taken at different temperatures, for as-grown $\mathrm{NaBr}: \mathrm{Mn}^{2+}$. $300 \mathrm{~K} ;---, 30 \mathrm{~K} ; \cdots, 6 \mathrm{~K}$.

formed. In all these cases the shape of the EPR band reflects the exchange interaction among closest $\mathrm{Mn}^{2+}$ ions [29].

The value of the bandwidth is $\Delta H_{\mathrm{pp}}=117 \pm 5 \mathrm{G}$ at room temperature. This value is unchanged down to about $30 \mathrm{~K}$. Below this temperature $\Delta H_{\mathrm{pp}}$ starts to increase slightly, its value at $6 \mathrm{~K}$ being $\Delta H_{\mathrm{pp}}=134 \mathrm{G}$. This behaviour can be associated with a $\mathrm{PF}$ of $\mathrm{Mn}^{2+}$ whose magnetic phase transition occurs well below $6 \mathrm{~K}$. Therefore it is consistent with the formation of the SP in our samples, as was established through Raman measurements [14]. In fact a similar behaviour of $\Delta H_{\mathrm{pp}}$ was observed in as-grown $\mathrm{NaCl}: \mathrm{Mn}^{2+}$ where the SP undergoes a para-antiferromagnetic phase transition at $T_{\mathrm{N}}=0.2 \mathrm{~K}$, reflecting the great distance of $797 \mathrm{pm}$ between nearest-neighbour $\mathrm{Mn}^{2+}$ ions [3, 4].

All the samples investigated give the same EPR signal depicted in figure 1 and so no traces of isolated $\mathrm{Mn}^{2+}$ ions truly dissoved in $\mathrm{NaBr}$ have been detected.

Figure 2 reports the emission and the corresponding excitation spectra for as-grown $\mathrm{NaBr}: \mathrm{Mn}^{2+}$. All the analysed samples give the same results. The excitation spectrum in the $320-530 \mathrm{~nm}$ region can be associated with the crystal field spectrum of $\mathrm{Mn}^{2+}$ in octahedral symmetry. No signs of local distortions lowering the $\mathrm{O}_{\mathrm{h}}$ symmetry are detected. Excitation and emission peaks together with the values of $B, C$ and $10 D q$ derived from the analysis are given in table 1.

Besides these crystal field bands there is another one, whose maximum lies at $214 \mathrm{~nm}$, giving rise to the same emission band peaked at $621.5 \mathrm{~nm}$ at $14 \mathrm{~K}$ (figure 2). This band whose intensity seems to increase when temperature is lowered is assigned to the ${ }^{4} \mathrm{~T}_{2}(\mathrm{G})+\left[{ }^{4} \mathrm{~A}_{1}(\mathrm{G}),{ }^{4} \mathrm{E}(\mathrm{G})\right]$ transition because its maximum is very close to the sum of the ${ }^{4} T_{2}(G)$ and ${ }^{4} A_{1}(G),{ }^{4} E(G)$ peak energies. Excitations of this kind arising from the exchange interaction between close $\mathrm{Mn}^{2+}$ ions cannot appear when truly isolated $\mathrm{Mn}^{2+}$ ions are involved, but they have been detected for several $\mathrm{PF}$ of $\mathrm{Mn}^{2+}$ in alkali halides $[5,6,12]$.

Other excitation bands due to transfer of unintentional impurities in our samples to $\mathrm{Mn}^{2+}$ were detected in the $225-310 \mathrm{~nm}$ region. Such excitation bands which normally do not give rise to the same emission band depicted in figure 2 shall be discussed in a future work.

The emission peak experiences a slight blue shift of $500 \mathrm{~cm}^{-1}$ on passing from $14 \mathrm{~K}$ to room temperatures. This fact discards an extrinsic origin for the emission, associated 




Figure 2. Emission band (right) appearing in the $550-700 \mathrm{~nm}$ region and the corresponding excitation spectra for as-grown $\mathrm{NaBr}: \mathrm{Mn}^{2+}$ taken at room temperature (-- ) and at $14 \mathrm{~K}$ (- - Assignment of excitation peaks is also given. The increase of the emission intensity in the neighbourhood of $550 \mathrm{~nm}$ in the spectrum taken at $14 \mathrm{~K}$ corresponds to the tail of the exciting light with a wavelength $\lambda=521 \mathrm{~nm}$.

Table 1. Position of the emission and excitation peaks depicted in figure 1 together with the derived values of $B, C$ and $10 \mathrm{Dq}$.

\begin{tabular}{|c|c|c|c|c|}
\hline \multirow[b]{2}{*}{ Peak } & \multicolumn{2}{|c|}{$\mathrm{RT}$} & \multicolumn{2}{|c|}{$14 \mathrm{~K}$} \\
\hline & $(n m)$ & $\left(\mathrm{cm}^{-1}\right)$ & $(\mathrm{nm})$ & $\left(\mathrm{cm}^{-1}\right)$ \\
\hline${ }^{4} \mathrm{~T}_{1}(\mathrm{G})$ & 511.8 & 19539 & 518.7 & 19279 \\
\hline${ }^{4} \mathrm{~T}_{2}(\mathrm{G})$ & 439.7 & 22743 & 444.0 & 22523 \\
\hline${ }^{4} \mathrm{~A}_{1}(\mathrm{G}),{ }^{4} \mathrm{E}(\mathrm{G})$ & $\sim 425$ & $\sim 23529$ & 419.6 & 23832 \\
\hline${ }^{4} \mathrm{~T}_{2}(\mathrm{D})$ & 370.5 & 26991 & 367.8 & 27189 \\
\hline${ }^{4} \mathrm{E}(\mathrm{D})$ & 357.3 & 27988 & 354.6 & 28201 \\
\hline${ }^{4} \mathrm{~T}_{1}(\mathrm{P})$ & 337.2 & 29656 & 333.3 & 30003 \\
\hline${ }^{4} \mathrm{~T}_{2}(\mathrm{G})+\left[{ }^{4} \mathrm{~A}_{1}(\mathrm{G}),{ }^{4} \mathrm{E}(\mathrm{G})\right]$ & & & 214.2 & 46685 \\
\hline$B$ & & 760.8 & & 772.0 \\
\hline$C$ & & 2924 & & 2962 \\
\hline $10 D q$ & & 5356 & & 5930 \\
\hline Emission $\left({ }^{4} \mathrm{~T}_{1}(\mathrm{G}) \rightarrow{ }^{6} \mathrm{~A}_{1}(\mathrm{~S})\right)$ & 601.0 & 16639 & 621.5 & 16090 \\
\hline
\end{tabular}

with the migration of the excitation and subsequent trapping by perturbed $\mathrm{Mn}^{2+}$ ions. Luminescence of this kind has been observed in $\mathrm{MnF}_{2}[31,32], \mathrm{Rb}_{2} \mathrm{MnCl}_{4}$ [33] and also in the $\mathrm{PF}$ formed in as-grown $\mathrm{RbCl}: \mathrm{Mn}^{2+}[25]$ and $\mathrm{LiF}: \mathrm{Mn}^{2+}[34]$ crystals. By contrast, as in the present case, the emission observed in the SP formed in as-grown $\mathrm{NaCl}: \mathrm{Mn}^{2+}$ is intrinsic and then corresponds to the radiative de-excitation of the previously photoexcited $\mathrm{Mn}^{2+}$ ion. As usual, this emission comes from the ${ }^{4} \mathrm{~T}_{1}^{*}(\mathrm{G}) \rightarrow{ }^{6} \mathrm{~A}_{1}(\mathrm{~S})$ transition involving the first relaxed electronic excited state, ${ }^{4} \mathrm{~T}_{1}^{*}(\mathrm{G})$. This behaviour can be favoured by the very weak exchange between closest $\mathrm{Mn}^{2+}$ ions in the SP of $\mathrm{NaCl}: \mathrm{Mn}^{2+}$. 
Table 2. Position of the ${ }^{4} \mathrm{~T}_{1}(\mathrm{G})$ and $\left[{ }^{4} \mathrm{~A}_{1},{ }^{4} \mathrm{E}(\mathrm{G})\right]$ peaks for several systems involving $\mathrm{Mn}^{2+}$ in sixfold coordination. The values of $10 \mathrm{Dq}$ have been derived from the analysis of all the crystal field peaks, always using the same procedure.

\begin{tabular}{lllllll}
\hline System & Complex & $\begin{array}{l}T \\
(\mathrm{~K})\end{array}$ & $\begin{array}{l}{ }^{4} \mathrm{~T}_{1}(\mathrm{G}) \\
(\mathrm{nm})\end{array}$ & $\begin{array}{l}{ }^{4} \mathrm{~A}_{1},{ }^{4} \mathrm{E}(\mathrm{G}) \\
(\mathrm{nm})\end{array}$ & $\begin{array}{l}10 \mathrm{Dq} \\
\left(\mathrm{cm}^{-1}\right)\end{array}$ & Reference \\
\hline $\mathrm{MnBr}_{2}$ & {$\left[\mathrm{MnBr}_{6}\right]^{4-}$} & 4.2 & 546.7 & 428.9 & 6480 & {$[18][19]$} \\
$\mathrm{Cd}_{0.85} \mathrm{Mn}_{0.15} \mathrm{Br}_{2}$ & {$\left[\mathrm{MnBr}_{6}\right]^{4-}$} & 13 & 539.5 & 427.5 & 6298 & {$[21]$} \\
$\mathrm{CsMnBr}_{3}$ & {$\left[\mathrm{MnBr}_{6}\right]^{4-}$} & 77 & 550.2 & 432.0 & 6330 & {$[22]$} \\
$\mathrm{NaBr}^{4-\mathrm{Mn}^{2+}}$ as-grown & {$\left[\mathrm{MnBr}_{6}\right]^{4^{-}}$} & 14 & 518.7 & 419.6 & 5930 & Present work \\
$\mathrm{CsMnBr}_{3} \cdot 2 \mathrm{H}_{2} \mathrm{O}$ & {$\left[\mathrm{MnBr}_{4}\left(\mathrm{H}_{2} \mathrm{O}\right)_{2}\right]^{4-}$} & 4.2 & 535.0 & 419.5 & 6484 & {$[37]$} \\
$\mathrm{Bi}_{4} \mathrm{Ge}_{3} \mathrm{O}_{12}: \mathrm{Mn}^{2+}$ & {$\left[\mathrm{MnO}_{6}\right]^{10^{-}}$} & 15 & 527.0 & 415.0 & 6850 & {$[38]$} \\
$\mathrm{MnCl}_{2}$ & {$\left[\mathrm{MnCl}_{6}\right]^{4-}$} & 77 & 542.0 & 422.0 & 6696 & {$[39]$} \\
$\mathrm{NaCl} \mathrm{Mn}^{2+}$ as-grown & {$\left[\mathrm{MnCl}_{6}\right]^{4-}$} & 14 & 525.4 & 415.5 & 6474 & {$[6]$ and } \\
$\mathrm{NH}_{4} \mathrm{MnCl}_{3}$ & {$\left[\mathrm{MnCl}_{6}\right]^{4-}$} & 10 & 513.1 & 416.1 & 5870 & {$[40]$} \\
$\mathrm{RbCdF}_{3}: \mathrm{Mn}^{2+}$ & {$\left[\mathrm{MnF}_{6}\right]^{4^{-}}$} & 300 & 512.0 & 396.4 & 7150 & {$[28]$} \\
\hline
\end{tabular}

Writing this exchange interaction as $J S_{1} \cdot S_{2}$ for a pair of nearest $\mathrm{Mn}^{2+}$ ions, $J \simeq$ $0.017 \mathrm{~cm}^{-1}$ for the ground state [30].

Lifetime measurements also support the formation of a $\mathrm{PF}$ in as-grown $\mathrm{NaBr}: \mathrm{Mn}^{2+}$. In fact in the case of $\mathrm{Mn}^{2+}$-doped $\mathrm{NaCl}$ the value $\tau=4 \mathrm{~ms}$ that we have measured at room temperature for the SP is much smaller than the value $\tau=30 \mathrm{~ms}$ corresponding to $\mathrm{Mn}^{2+}$ ions truly dissolved in the host lattice [35]. The latter situation is also found, for instance, in $\mathrm{RbMn}_{0.4} \mathrm{Mg}_{0.6} \mathrm{~F}_{3}$, where $\tau=40 \mathrm{~ms}$ [36]. Although no data of $\tau$ have been reported for isolated $\mathrm{Mn}^{2+}$ ions in $\mathrm{NaBr}$ (see $\$ 4$ ), our first measurements giving $\tau \simeq$ $8 \mathrm{~ms}$ for as-grown $\mathrm{NaBr}: \mathrm{Mn}^{2+}$ suggest in fact the existence of a PF.

The crystal field spectra of $\mathrm{Mn}^{2+}$ in insulators reflects essentially the local environment around $\mathrm{Mn}^{2+}$. An important point to be studied in the present case is whether the position of the ${ }^{4} \mathrm{~A}_{1}(\mathrm{G}),{ }^{4} \mathrm{E}(\mathrm{G})$ peak determines unambiguously the existence of $\mathrm{MnBr}_{6}^{4-}$ octahedra or not [23]. In table 2 we have collected the positions of the ${ }^{4} \mathrm{~T}_{1}(\mathrm{G})$ and $\left[{ }^{4} \mathrm{~A}_{1}(\mathrm{G}),{ }^{4} \mathrm{E}(\mathrm{G})\right]$ peaks for several systems involving $\mathrm{Mn}^{2+}$ in $\mathrm{O}_{\mathrm{h}}$ symmetry as well as the corresponding values of $10 \mathrm{Dq}$.

Table 2 points out that if we only look at the $\left[{ }^{4} A_{1}(G),{ }^{4} E(G)\right]$ peak, the complexes involving some $\mathrm{O}^{2-}, \mathrm{H}_{2} \mathrm{O}$ or $\mathrm{Cl}^{-}$ligands could also be related to the experimental value observed in $\mathrm{NaBr}: \mathrm{Mn}^{2+}$. However, the absence of the infrared band associated with the stretching mode of $\mathrm{OH}^{-}$discards the presence of $\mathrm{H}_{2} \mathrm{O}$ as ligand in our samples. The same situation happens as regards $\mathrm{Cl}^{-}$. On the other hand, neither the Stokes shift measured in the present case (table 3) nor the $10 \mathrm{Dq}$ value support the existence of $\mathrm{MnO}_{6}$ octahedra. Mixed complexes $\mathrm{MnBr}_{x} \mathrm{O}_{6-x}$ are difficult to conciliate with the apparent $\mathrm{O}_{\mathrm{h}}$ symmetry and with $10 \mathrm{Dq}$ values smaller than that for $\mathrm{MnBr}_{2}$. This fact is against what is expected when $\mathrm{Br}^{-}$is substituted by oxygen [23].

A positive proof of the presence of $\mathrm{MnBr}_{6}^{4-}$ octahedra is however conveyed by the vibrational progression barely seen in the ${ }^{4} \mathrm{~T}_{1}(\mathrm{G})$ excitation band at $14 \mathrm{~K}$ but well resolved in its second derivative spectrum (figure 3 ). The frequency associated with such a progression, $\Omega^{*}=130 \pm 7 \mathrm{~cm}^{-1}$, is very close to the $A_{1 \mathrm{~g}}$ frequency $\Omega=126 \mathrm{~cm}^{-1}$ seen through Raman spectroscopy on the same crystal, which corresponds to the breathing mode of $\mathrm{MnBr}_{6}^{4-}$ around $\mathrm{Mn}^{2+}$ in the SP [14]. A similar situation has been encountered 
Table 3. Value of the Stokes shift $\Delta E_{\mathrm{S}}$ for several systems involving $\mathrm{Mn}^{2-}$ in octahedral coordination.

\begin{tabular}{lcll}
\hline System & $T(\mathrm{~K})$ & $\Delta E_{\mathrm{S}}\left(\mathrm{cm}^{-1}\right)$ & Reference \\
\hline $\mathrm{MnBr}_{2}$ & 10 & 2825 & {$[20]$} \\
$\mathrm{NaBr}: \mathrm{Mn}^{2-}$ as-grown & 14 & 3190 & Present work \\
$\mathrm{NaCl}: \mathrm{Mn}^{2+}$ as-grown & 14 & 3000 & Present work \\
$\mathrm{MnCl}_{2}$ & 10 & 2855 & {$[20]$} \\
$\mathrm{Bi}_{4} \mathrm{Ge}_{3} \mathrm{O}_{12}: \mathrm{Mn}^{2+}$ & 15 & 1734 & {$[38]$} \\
$\mathrm{RbCdF}_{3}: \mathrm{Mn}^{2-}$ & 300 & 1525 & {$[28]$} \\
\hline
\end{tabular}

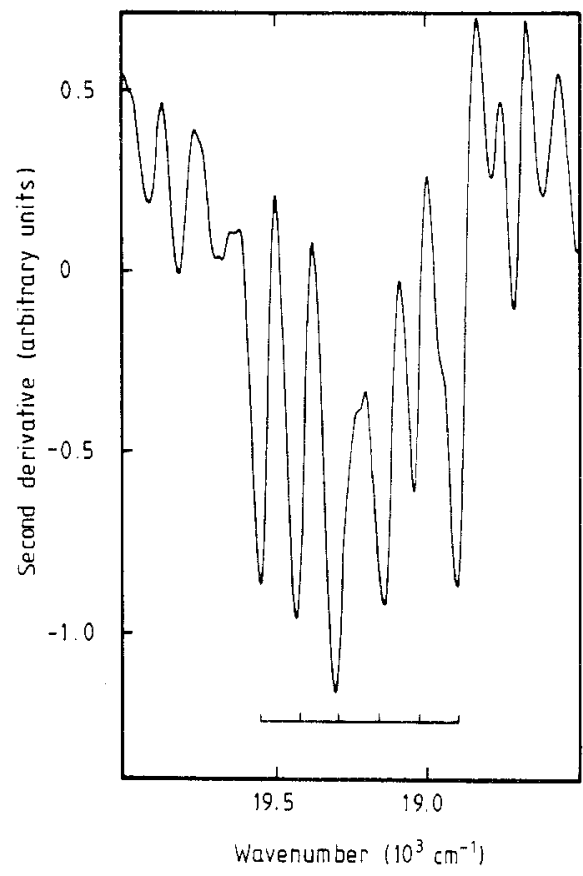

Figure 3. Second derivative of the ${ }^{4} T_{1}(G)$ excitation band showing the existence of a vibrational progression involving a phonon frequency $\Omega^{*}=$ $130 \pm 7 \mathrm{~cm}^{-1}$.

for the SP in $\mathrm{NaCl}: \mathrm{Mn}^{2+}$ [41]. It is important to say that both $\Omega$ and $\Omega^{*}$ frequencies must not be the same, but they could be very similar. In fact $\Omega$ corresponds to the electronic ground state while $\Omega^{*}$ is related to the excited ${ }^{4} T_{1}(G)$ state.

Some information on vibrational modes coupled to the electronic states can also be reached through the analysis of the Stokes shift $\Delta E_{\mathrm{s}}$ and the width $\Delta H$ of the ${ }^{4} \mathrm{~T}_{1}(\mathrm{G})$ band. Assuming that the electronic states are coupled to only one averaged mode of frequency $\Omega$, the expressions for $\Delta E_{\mathrm{s}}$ and $\Delta H$ at $0 \mathrm{~K}$ are [42]

$$
\begin{aligned}
& \Delta E_{\mathrm{s}}=2 S \hbar \Omega \\
& \Delta H=2.36 \sqrt{S} \hbar \Omega
\end{aligned}
$$

where $S$ is the Huang-Rhys factor.

In the present case, at $14 \mathrm{~K}, \Delta E_{\mathrm{s}}=3190 \mathrm{~cm}^{-1}$ while $\Delta H=880 \mathrm{~cm}^{-1}$ for the ${ }^{4} \mathrm{~T}_{1}(\mathrm{G})$ excitation peak. Using equation (1) we get $\Omega \simeq 90 \mathrm{~cm}^{-1}, S \simeq 18$. The value $\Omega \simeq 90 \mathrm{~cm}^{-1}$ 
for the averaged mode is then compatible with that of $\Omega=130 \mathrm{~cm}^{-1}$ related to the breathing mode of $\mathrm{MnBr}_{6}^{4--}$.

The analysis of the reported EPR and optical data is thus consistent with the presence of a $\mathrm{PF}$ involving $\mathrm{MnBr}_{6}^{4-}$ octahedra and whose magnetic phase transition lies well below $6 \mathrm{~K}$. Therefore it could in fact correspond to the SP as inferred from Raman experiments [14].

\section{Dependence of the crystal field spectrum on the $\mathrm{Mn}^{2+}-\mathrm{Br}^{-}$distance}

This section is devoted to investigating to what extent the spectroscopic differences involved in $\mathrm{MnBr}_{6}^{4-}$ complexes and pointed out in table 2 can be understood on the basis of different metal-ligand distances $R$.

It is worth recalling here that for the case of $\mathrm{Mn}^{2+}$-doped fluoroperovskites (like $\mathrm{KZnF}_{3}, \mathrm{CsCaF}_{3}$ etc) it has been shown that the variations undergone by the crystal field spectrum are essentially due to different $\mathrm{Mn}^{2+}-\mathrm{F}^{-}$distances in the $\mathrm{MnF}_{6}^{4-}$ complex [28, $43,44]$. Such different metal-ligand distances reflect in fact a different chemical pressure exerted by the rest of the lattice upon the $\mathrm{MnF}_{6}^{4-}$ complex. For these systems it has been demonstrated that $10 \mathrm{Dq}$ is the most sensitive parameter to detect $R$ changes, being proportional to $R^{-4.7}$.

When pure compounds of $\mathrm{Mn}^{2+}$ rather than isolated complexes diluted in a host lattice are considered, one must be cautious in the application of the preceding ideas. In these systems the nearest $\mathrm{Mn}^{2+}$ ions often share one or several ligands. This makes it difficult, in principle, to compare directly the properties of an isolated complex with those coming from a compound with the same ligands, but where some of them are shared. For instance, if we assume that the actual charge $q(M)$ on $\mathrm{Mn}^{2+}$ is the same for both situations, the electronic charge on ligands cannot be the same unless $q(M)=2$. This extreme situation, implying that bonding is purely ionic, occurs however for systems involving $\mathrm{MnF}_{6}^{4-}$ units and so the differences between crystal field spectra of $\mathrm{RbMnF}_{3}$, $\mathrm{KMnF}_{3}, \mathrm{KZnF}_{3}: \mathrm{Mn}^{2+}$ etc are essentially due to different $\mathrm{Mn}^{2+}-\mathrm{F}^{-}$distances [28, 44]. When covalency increases the variations undergone by crystal field spectra cannot be explained only through this simple idea. As an example, for $\mathrm{NH}_{4} \mathrm{MnCl}_{3}$, where each ligand is shared by two adjacent $\mathrm{Mn}^{2+}$ ions and $R=252 \mathrm{pm}$ [40], it is derived that (table 2) $10 \mathrm{Dq}=5870 \mathrm{~cm}^{-1}$. This value is smaller than $10 \mathrm{Dq}=6470 \mathrm{~cm}^{-1}$ found for the SP in $\mathrm{NaCl}: \mathrm{Mn}^{2+}$ at $14 \mathrm{~K}$ where $R=258 \mathrm{pm}$ and ligands are not shared at all.

Having in mind these results, let us compare the crystal field spectrum of the SP in $\mathrm{NaBr}: \mathrm{Mn}^{2+}$ with that for $\mathrm{MnBr}_{2}$ and $\mathrm{Cd}_{0.85} \mathrm{Mn}_{0.15} \mathrm{Br}_{2}$. The $10 \mathrm{Dq}$ values reported in table 2 suggest that $R$ values increase through the series $\mathrm{MnBr}_{2}-\mathrm{Cd}_{0.85} \mathrm{Mn}_{0.15} \mathrm{Br}_{2}-\mathrm{NaBr}: \mathrm{Mn}^{2+}$. This idea is qualitatively supported by the $\Omega^{*}\left(\mathrm{~A}_{1 \mathrm{~g}}\right)$ frequencies provided by the vibrational progressions in the ${ }^{4} \mathrm{~T}_{1}(\mathrm{G})$ band. Indeed, such a value decreases through the series and is equal to $151 \pm 5 \mathrm{~cm}^{-1}, 141 \pm 3 \mathrm{~cm}^{-1}$ and $130 \pm 7 \mathrm{~cm}^{-1}$ for $\mathrm{MnBr}_{2}$ [18], $\mathrm{Cd}_{0.85} \mathrm{Mn}_{0.15} \mathrm{Br}_{2}[21]$ and $\mathrm{NaBr}: \mathrm{Mn}^{2+}$ respectively.

On the other hand, the $\mathrm{Mn}^{2+}-\mathrm{Br}^{-}$distance in $\mathrm{MnBr}_{2}, R=269 \mathrm{pm}$, is in fact $7 \mathrm{pm}$ smaller than the sum of ionic radii corresponding to $\mathrm{Mn}^{2+}$ and $\mathrm{Br}^{-}$. This suggests that in $\mathrm{NaBr}: \mathrm{Mn}^{2+} R$ should lie between $269 \mathrm{pm}$ and $276 \mathrm{pm}$. If now we assume that changes in $10 \mathrm{Dq}$ are only due to $R$ changes and that $10 \mathrm{Dq}$ is proportional to $R^{-p}(p \approx 5)$, we find $R=273.8 \mathrm{pm}$ for $\mathrm{NaBr}: \mathrm{Mn}^{2+}$ and $R=270.5$ pm for $\mathrm{Cd}_{0.85} \mathrm{Mn}_{0.15} \mathrm{Br}_{2}$. The last figure implies $\Delta R=1.5 \mathrm{pm}$ between the $R$ values for $\mathrm{Cd}_{0.85} \mathrm{Mn}_{0.15} \mathrm{Br}_{2}$ and $\mathrm{MnBr}_{2}$ and compares 
well with the value $\Delta R=1.9 \pm 0.4 \mathrm{pm}$ between $\mathrm{RbCdF}_{3}: \mathrm{Mn}^{2+}$ [43] and the average $\mathrm{Mn}^{2+} \mathrm{F}^{-}$distance in $\mathrm{MnF}_{2}$, equal to $212 \mathrm{pm}$.

A salient feature of the $14 \mathrm{~K}$ crystal field spectrum depicted in figure 2 is the position of the $\left[{ }^{4} A_{1}(G),{ }^{4} E(G)\right]$ peak at $419.6 \mathrm{~nm}$. Such a peak, denoted $E_{3}$, appears at $428.9 \mathrm{~nm}$ for $\mathrm{MnBr}_{2}$.

Zahner and Drickamer [16] measured a variation of $E_{3}$ under hydrostatic pressure equal to $\left(\partial E_{3} / \partial P\right)_{T}=-9 \mathrm{~cm}^{-1} / \mathrm{kbar}$ at room temperature, which implies

$$
\left(\partial E_{3} / \partial R\right)_{T} \simeq+50 \mathrm{~cm}^{-1} / \mathrm{pm}
$$

for $\mathrm{MnBr}_{6}^{4-}$, assuming a local bulk modulus $B \simeq 500 \mathrm{kbar}$. Through this figure it is then possible to understand qualitatively why the ${ }^{4} \mathrm{~A}_{1}(\mathrm{G}),{ }^{4} \mathrm{E}(\mathrm{G})$ peaks of $\mathrm{NaBr}: \mathrm{Mn}^{2+}$ and $\mathrm{Cd}_{0.85} \mathrm{Mn}_{0.15} \mathrm{Br}_{2}$ are blue-shifted with respect to that for $\mathrm{MnBr}_{2}$. Quantitatively, such a figure accounts for the $76 \mathrm{~cm}^{-1}$ shift of $\mathrm{Cd}_{0.85} \mathrm{Mn}_{0.15} \mathrm{Br}_{2}$, putting $\Delta R=1.5 \mathrm{pm}$. Nevertheless only about half of the $517 \mathrm{~cm}^{-1}$ shift corresponding to $\mathrm{NaBr}: \mathrm{Mn}^{2+}$ is explained through this mechanism putting $\Delta R=4.8 \mathrm{pm}$ in equation (2). This indicates that the different crystal structures of the SP and $\mathrm{MnBr}_{2}$ have an influence upon such a shift. A similar situation appears when $\mathrm{E}_{3}$ for $\mathrm{MnCl}_{2}$ and the SP in $\mathrm{NaCl}: \mathrm{Mn}^{2+}$ are compared (table 2).

Although the preceding discussion indicates that $\left(\partial E_{3} / \partial R\right)_{T}$ is positive for $\mathrm{MnBr}_{6}^{4-}, \mathrm{E}_{3}$ appears to undergo a blue shift rather than a red shift upon cooling, as is pointed out in figure 2 and table 1 . A blue shift of this kind is indeed observed for example for $\mathrm{CsMnBr}_{3} \cdot 2 \mathrm{H}_{2} \mathrm{O}$ [37], $\mathrm{RbMnF}_{3}$ [45], or the SP in $\mathrm{NaCl}: \mathrm{Mn}^{2+}$ [6]. In the latter case $E_{3}=23861 \mathrm{~cm}^{-1}$ at room temperature while $E_{3}=24067 \mathrm{~cm}^{-1}$ at $14 \mathrm{~K}$. This curious situation arises because, in general $(\partial E / \partial T)_{P}$, where $E$ may be an optical excitation peak, is not only deternined by the changes of volume due to thermal expansion effects but also given by

$$
(\partial E / \partial T)_{P}=-3 \alpha B(\partial E / \partial P)_{T}+(\partial E / \partial T)_{V}
$$

Here $\alpha$ is the linear thermal expansion coefficient while $(\partial E / \partial T)_{V}$ corresponds to the so-called explicit temperature term. For the case of the ${ }^{4} T_{1}(G)$ peak energy $E_{1}$ in $\mathrm{RbMnF}_{3}$ it has been shown [45] that both terms have the same sign and the explicit term gives $60 \%$ of the total $\left(\partial E_{1} / \partial T\right)_{P}$ value. Figure 2 and table 1 point out that in the present case $\left(\partial E_{1} / \partial T\right)_{P}$ is positive as well. For the ${ }^{4} \mathrm{~A}_{1}(\mathrm{G}),{ }^{4} \mathrm{E}(\mathrm{G})$ peak of $\mathrm{Mn}^{2+}$ complexes, however, the situation appears to be rather different, influenced by the much lower values of $(\partial E / \partial P)_{T}$ when compared to the figures found for the ${ }^{4} \mathrm{~T}_{1}(\mathrm{G})$ peak strongly dependent upon $10 \mathrm{Dq}$. This way, $\left(\partial E_{1} / \partial T\right)_{P}=-34.7 \mathrm{~cm}^{-1} / \mathrm{kbar}$ for $\mathrm{MnBr}_{2}[16]$, which is 3.8 times higher than the value corresponding to the $\left[{ }^{4} A_{1}(G),{ }^{4} E(G)\right]$ peak.

Apparently in the cases mentioned $\left(\partial E_{3} / \partial T\right)_{P}$ is clearly dominated by the explicit term, which moreover has the opposite sign to that of the implicit contribution reflecting the effects of thermal expansion. A microscopic analysis of this situation will be reported in the near future.

Before ending this section we would like to remark that the emission peak is more sensitive to temperature changes than the corresponding ${ }^{4} \mathrm{~T}_{1}(\mathrm{G})$ excitation peak. Indeed, while the latter peak experiences a shift of $260 \mathrm{~cm}^{-1}$ on passing from $14 \mathrm{~K}$ to room temperature, the corresponding value for the former one is $530 \mathrm{~cm}^{-1}$. A similar situation to this one is found for the SP in $\mathrm{NaCl}: \mathrm{Mn}^{2+}$, where the Stokes shift $\Delta E_{\mathrm{s}}$ is equal to $2560 \mathrm{~cm}^{-1}$ at room temperature while $\Delta E_{\mathrm{s}}=3000 \mathrm{~cm}^{-1}$ at $14 \mathrm{~K}$. Although these data appear to indicate that the emission peak is more sensitive than the corresponding 


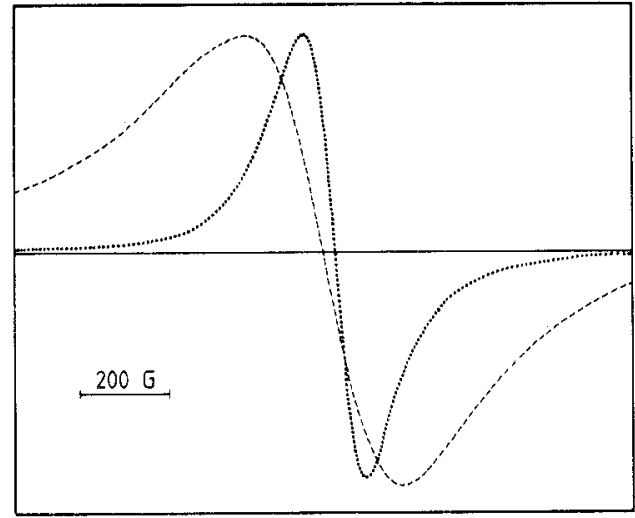

Figure 4. EPR spectrum at $7 \mathrm{~K}$ of a $\mathrm{NaBr}: \mathrm{Mn}^{2+}$ crystal after quenching at $600^{\circ} \mathrm{C}$ (broken curve). For comparison purposes the corresponding spectrum of an as-grown sample is also included (dotted curve).

${ }^{4} \mathrm{~T}_{1}(\mathrm{G})$ excitation peak to $R$ changes, measurements under hydrostatic pressures are required to verify this guess.

\section{Effects of quenching}

Figures 4 and 5 collect the EPR and crystal field spectra of $\mathrm{NaBr}: \mathrm{Mn}^{2+}$ crystals after a severe quenching at $600^{\circ} \mathrm{C}$. The EPR spectrum does not give any evidence of the appearance of isolated $\mathrm{Mn}^{2+}$. By contrast, a single EPR line is observed although now $\Delta H_{\mathrm{pp}}=$ $340 \mathrm{G}$ at $7 \mathrm{~K}$, which is 2.5 times higher than the value for the as-grown crystals at $7 \mathrm{~K}$. At room temperature $\Delta H_{\mathrm{pp}}$ is a little smaller, being equal to $300 \mathrm{G}$.

The changes observed in the excitation and emission spectra (figure 5, tables 1 and 4) are smaller but allow one to distinguish the as-grown from the quenched crystal. This way the emission band of the quenched crystal has its maximum at $633 \mathrm{~nm}$ at $77 \mathrm{~K}$,

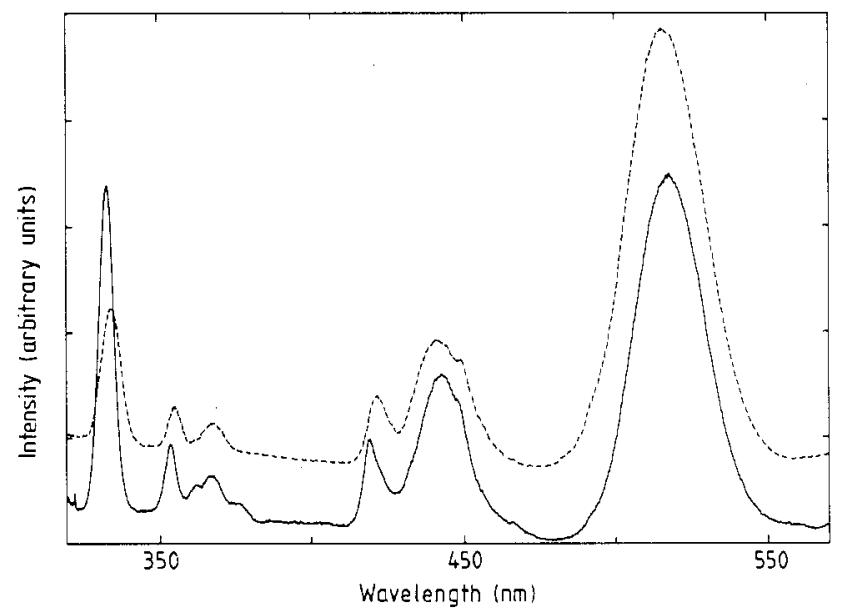

Figure 5. Crystal-field excitation spectrum at $77 \mathrm{~K}$ of a $\mathrm{NaBr}: \mathrm{Mn}^{2+}$ crystal after quenching at $600^{\circ} \mathrm{C}$ (broken curve), compared to that of an as-grown sample (full curve). 
Table 4. Position of the emission and excitation peaks corresponding to the quenched crystal measured at $77 \mathrm{~K}$ (see figure 5). The values of $B, C$ and $10 D q$ are also given.

\begin{tabular}{lcc}
\hline & & \\
\hline${ }^{4} \mathrm{~T}_{1}(\mathrm{G})$ & $(\mathrm{nm})$ & $\left(\mathrm{cm}^{-1}\right)$ \\
${ }^{4} \mathrm{~T}_{2}(\mathrm{G})$ & 516.2 & 19372 \\
${ }^{4} \mathrm{~A}_{1}(\mathrm{G}),{ }^{4} \mathrm{E}(\mathrm{G})$ & 442.4 & 22604 \\
${ }^{4} \mathrm{~T}_{2}(\mathrm{D})$ & 422.2 & 23685 \\
${ }^{4} \mathrm{E}(\mathrm{D})$ & 368.1 & 27167 \\
${ }^{4} \mathrm{~T}_{1}(\mathrm{P})$ & 355.7 & 28114 \\
$B$ & 335.0 & 29851 \\
${ }^{B}$ & & 772.6 \\
$10 D q$ & & 2932 \\
Emission $\left({ }^{4}{ }^{4} \mathrm{~T}_{1}(\mathrm{G}) \rightarrow{ }^{6} \mathrm{~A}_{1}(\mathrm{~S})\right)$ & 633.0 & 15798 \\
\hline
\end{tabular}

while it is placed at $621.5 \mathrm{~nm}$ for the as-grown crystal. Also $10 \mathrm{Dq}=5680 \mathrm{~cm}^{-1}$ for the quenched crystal is about $4 \%$ smaller than the value found for the as-grown sample.

The preceding data point out that quenching has not been able to dissolve the $\mathrm{Mn}^{2+}$ ions into the $\mathrm{NaBr}$ host lattice. On the other hand, the results shown in figures 4 and 5 can be associated with the formation of a new PF of $\mathrm{Mn}^{2+}$ which also remains paramagnetic well below $7 \mathrm{~K}$. Another possibility lies in the formation of very small grains of SP in which distances are slightly changed. To elucidate which of these assumptions is the right one requires further investigation.

It is worth pointing out here that Rubio et al [24], working with $\mathrm{NaBr}$ crystals doped with $130 \mathrm{ppm}$ of $\mathrm{Mn}^{2+}$ and $8 \mathrm{ppm}$ of $\mathrm{Eu}^{2+}$, also detect an EPR line with Lorentzian shape and having $\Delta H_{\mathrm{pp}}=300 \pm 30 \mathrm{G}$ at room temperature. Moreover, they also indicate that such a line does not disappear even after heating the crystal at $800 \mathrm{~K}$ for several hours. Despite the similarity with some of the results reported here, Rubio et al [24] have not identified any EPR line with $\Delta H_{\mathrm{pp}} \simeq 117 \mathrm{G}$ in their samples.

\section{Final remarks}

This work has shown the usefulness of studying several macroscopic properties as a function of temperature for reaching reasonable conclusions on the existence and characteristics of PF formed in doped insulator materials. Accordingly, the conclusions recently reached [46] on the formation of the sP in $\mathrm{CsCl}: \mathrm{Eu}^{2+}, \mathrm{Mn}^{2+}$ are to be viewed with caution. Indeed in such a work the EPR spectrum was only taken at room temperature.

In the present case, none of the EPR and optical data shown here is against the formation of the SP in our as-grown $\mathrm{NaBr}: \mathrm{Mn}^{2+}$ crystal, as was inferred from Raman measurements [14]. As in the SP the distance between closest $\mathrm{Mn}^{2+}$ ions can be derived from the lattice parameter of the corresponding alkali halide, the value of the exchange constant $J$ can be inferred from the high-temperature value $\Delta H_{\mathrm{pp}}=117 \mathrm{G}$ using the theory by Anderson and Weiss [29] already applied to the SP in $\mathrm{NaCl}: \mathrm{Mn}^{2+}[30]$. In doing so a value $J=0.014 \mathrm{~cm}^{-1}$ is found which is $80 \%$ of that obtained for the SP in $\mathrm{NaCl}: \mathrm{Mn}^{2+}$. 
Apparently the changes of $10 \mathrm{Dq}$ on going from as-grown $\mathrm{NaBr}: \mathrm{Mn}^{2+}$ to $\mathrm{Cd}_{0.85} \mathrm{Mn}_{0.15} \mathrm{Br}_{2}$ and $\mathrm{MnBr}_{2}$ can reasonably be related to a decrease of the metal-ligand distance through this series. Although in these cases no truly isolated $\mathrm{MnBr}_{6}^{4-}$ are involved and in $\mathrm{MnBr}_{2}$ there are ligands shared between adjacent $\mathrm{Mn}^{2+}$ ions, the very low value of $T_{\mathrm{N}}$ may somewhat explain that situation. This way for $\mathrm{MnBr}_{2}, T_{\mathrm{N}}$ is only equal to $2.16 \mathrm{~K}$ while, for instance, $T_{\mathrm{N}}=105 \mathrm{~K}$ for $\mathrm{NH}_{4} \mathrm{MnCl}_{3}$.

Further work on $\mathrm{NaBr}: \mathrm{Mn}^{2+}$ as well as on the PF formed in $\mathrm{Mn}^{2+}$-doped $\mathrm{LiCl}$ and $\mathrm{KBr}$ is now under way.

\section{Acknowledgment}

This work has been supported by the CICYT under Project No PB 86-0304.

\section{References}

[1] Agulló-López F, Calleja J M, Cussó F, Jaque F and López F J 1986 Prog. Mater. Sci. 30

[2] Chapman J A and Lilley E 1975 J. Mater. Sci. 101154

[3] Gómez-Sal J C, Moreno M, Rodríguez F, Revex A and Tholence J L 1987 J. Phys. C: Solid State Phys. 20 L 421

[4] Gómez-Sal J C, Rodríguez F, Moreno M and Tholence J L 1988 Phys. Rev. B 37454

[5] Rodríguez F, Moreno M and Rousseau J J 1987 Cryst. Lattice Defects and Amorph. Mater. 16161

[6] Rodríguez F, Moreno M, Jaque F and López F J 1983 J. Chem. Phys. 781

[7] Benedek G, Calleja J M, Capelletti R and Breitschwerdt A 1984 J. Phys. Chem. Solids 45741

[8] De Andrés A, Calleja J M, Pollini I and Benedek G 1985 J. Chem. Phys. 834967

[9] Calleja J M, Ruiz A, Flores F, Velasco V R and Lilley E 1980 J. Phys. Chem. Solids 411367

[10] Yacamán M, Hobbs L W and Goringe M J 1977 Phys. Status Solidi 39 K85

[11] Rodríguez F, Moreno M, Gómez-Sal J C and Janot C 1989 Physica B 156, 15733

[12] Moreno M, Rodríguez F, Aramburu J A, Jaque F and López F J 1983 Phys. Rev. B 286100

[13] De Andrés A, Calleja J M, López F J, Jaque F, Rodríguez F and Moreno M 1983 Radiat. Effects 75241

[14] De Andrés A, Calleja J M, Pollini I and Benedek G 1986 J. Molec. Struct. 14371

[15] Pappalardo R 1959 J. Chem. Phys. 311050

[16] Zahner J C and Drickamer H G 1961 J. Chem. Phys. 351483

[17] Farge Y, Régis M and Royce B S H 1976 J. Physique 37637

[18] Pollini 1, Spinolo G and Benedek G 1980 Phys. Rev. B 226369

[19] Hoekstra H J W M, Folkersma H F and Haas C 1985 Physica 128 B 133

[20] Ronda C R, Siekman H H and Haas C 1987 Physica 144 B 331

[21] McCarthy P J and Güdel H U 1985 Inorg. Chem. 25838

[22] McPherson G L, Aldrich H S and Chang J R 1974J. Chem. Phys. 60534

[23] Jorgensen C-K 1971 Modern Aspects of Ligand Field Theory (Amsterdam: North-Holland) p 297

[24] Rubio J, Muñoz A and García J 1987 Phys. Rev. B 368115

[25] Rodriguez F and Moreno M 1986 Solid State Commun. 58701

[26] Marco de Lucas C and Rodriguez F 1989 Rev. Sci. Instrum. at press

[27] Curie D, Barthou C and Canny B 1974 J. Chem. Phys. 613048

[28] Rodríguez F and Moreno M 1986 J. Chem. Phys. 84692

[29] Anderson P W and Weiss P R 1953 Rev. Mod. Phys. 25269

[30] Moreno M, Gómez-Sal J C, Aramburu J A, Rodrígues F, Tholence J L and Jaque F 1984 Phys. Rev. B 294192

[31] Wilson B, Yen W, Hegarty J and Imbusch G 1979 Phys. Rev. B 194238

[32] Rodríguez F, Moreno M, Baruchel J and Henry J Y 1985 J. Physique 46155

[33] Kambli U and Güdel H U 1984 Inorg, Chem. 233479

[34] Rodriguez F and Moreno M 1985 J. Physique 46151

[35] Cywinski R, Mugenski E, Nowy-Wiechula W and Wiechula J 1985 Phys. Status Solidi b 132 K91

[36] Di Bartolo B, Danko J and Pacheco D 1987 Phys. Rev. B 356386 
[37] Day P and Dubicki L 1973 J. Chem. Soc. Faraday Trans, II 69363

[38] Jiménez E, Arizmendi L and Cabrera J M 1988 J. Phys. C: Solid State Phys. 211299

[39] Regis M and Farge Y 1976 J. Physique 37627

[40] Agulló-Rueda F, Calleja J M, Jaque F, Tornero J D and Palacio F 1986 Solid State Commun. 60331

[41] Jaque F, López F, Cussó F, Meseguer F, Agulló-López F and Moreno M 1983 Solid State Commun. 47 103

[42] Fitchen D B 1968 Physics of Color Centers ed. W B Fowler (New York: Academic Press) p 299

[43] Rodríguez F, Moreno M, Tressaud A and Chaminade J P 1987 Cryst. Lattice Defects and Amorph. Mater. 16221

[44] Flórez M, Seijo L and Pueyo L 1986 Phys. Rev. B 231200

[45] Rodríguez F, Moreno M, Dance J M and Tressaud A 1989 Solid State Commun. 6967

[46] Tewari K K, Pandey S D and Chand P 1989 Solid State Commun. 691109 